\title{
Periodontal Porameters Alterations with Use of Conventional Bracket and Self-ligating Brackets
}

\author{
Dr Manish Bajracharya,' Dr Ranjita Shrestha Gorkhali, ${ }^{2}$ Dr Abhilasha Khanal, ${ }^{3}$ \\ Dr Neesha Shrestha, ${ }_{4}$ Dr Umesh Parajulis \\ 'Associate Professor, Orthodontic Unit, ${ }^{2}$ Assistant Professor, Periodontology and implantology Unit, \\ ${ }^{3}$ Assistant Professor, Orthodontic Unit, ${ }^{4}$ Orthodontist, Orthodontic Unit, Dental Department, National Academy of \\ Medical Sciences (NAMS), Bir Hospital, Mahaboudha, Kathmandu, Nepal, \\ Associate Professor, Orthodontic Department, Gandaki Medical College, Pokhara, Nepal
}

\section{ABSTRACT}

Introduction: Different bracket systems are available in the market claiming to have some advantage over the other. Conventional brackets and the self-ligating brackets are the most common. Though both the systems work basically similarly, the difference between the two system is principally in the ligating technique. The advantage of conventional brackets claimed are faster tooth movements and improved oral health of the patient.

Materials \& Method: A total number of 20 patients were shorted from the waiting list meeting the selection criteria. With the help of random number generator, two groups with 10 subjects each were created for conventional brackets (0.022 Slot MBT brackets) and self-ligating brackets ( 0.022 Slot DAMON prescription) respectively. The patients were blinded regarding the selection of the brackets. The brackets were bonded according to the random number allocation. After the bonding, the periodontal parameters i.e. gingival index (GI), plaque Index (PI) were measured again at an interval of 60 (T1) and 120 days (T2). Periodontal indices were calculated by summing the mean score of each examined tooth and dividing by the number of the evaluated teeth. Data collection was done with the help of a periodontal probe. All the records were taken by the same periodontist to avoid inter-examiner variability. To reassure that there is no any intra-examiner variation for periodontal status, the same periodontist re-measured the periodontal parameters again of 10 individuals selected randomly after 7 days from the initial measurements. To examine the intra-examination variability, Dahlberg's formula was used between the two readings taken at a span of 7 days of the same subjects. The mean value of Plaque index and Gingival index was checked for normal distribution applying KolmogorovSmirnov test. One-way ANOVA test was applied for comparison between and within groups for plaque index and Gingival index during three different period in Conventional brackets and Self-ligating brackets. Post hoc Bonferroni test was applied for multiple comparison. Independent t-test was applied for comparison between conventional brackets and self-ligating brackets to compare the plaque index and gingival index. All data were test were analyzed at $P<0.05$.

Result: There was no any significant difference between TO and T1 and between $\mathrm{T} 1$ and $\mathrm{T} 2$ in both the conventional brackets and self-ligating brackets. However, there was statistical difference between the time period from TO to T2. There was also no any significant difference between conventional bracket and self-ligating brackets in terms of plaque index and gingival index.

Conclusion: There are no advantages of self-ligating brackets over conventional brackets in terms of periodontal status.

Keywords: Conventional brackets, Periodontal status, Self-ligating brackets.

\section{INTRODUCTION}

The oral cavity is populated by diverse groups of bacterial and viral pathogen and if there is any biological imbalance between the host and the microorganism, then there is high chance of dental caries and periodontal problem. ${ }^{1-3}$ Accumulation of plaque on the tooth surface close to the free gingiva causes gingival inflammation as a result of direct release of toxins, polysaccharides or enzymes and/or indirectly from the host's body's immune response. ${ }^{4}$ The severity of the infection and the activity of the periodontal pathogens are controlled by the protective factors of the host such as the epithelium, gingival crevicular fluid (GCF) flow, the immunity of the host and the cell regenerating capacity. ${ }^{5,6}$

When a person is under orthodontic treatment, the oral environment may change owing to the diverse types of material being used in the process ranging from solid to elastic materials such as bracket, modules, elastics, wires etc. ${ }^{7.8}$ Besides, the types of brackets and their design, surface roughness, the types of accessories like the ligature ties, modules, zigs etc. may also be 
the cause of microbial harvesting. ${ }^{9-11}$ Active forces are applied with the help of brackets on the tooth leading to its desired movements. Many bracket systems are available and the most common are the conventional brackets and the self-ligating brackets. Though both the system work on the same principle, the principle difference is the ligating system. Different system of orthodontic treatment has been advocated claiming to be superior for oral hygiene control than the rest.8,12,13 Most commonly, conventional brackets are used as it is relatively cheaper than the self-ligating bracket. However, since ligature ties or modules are not needed in self-ligating brackets, it is claimed that bacterial harvest is less in the self-ligating brackets compared to conventional brackets. ${ }^{14,15}$ The self-ligating brackets claim to be more oral hygiene friendly as it does not have any external ligating system. However, in conventional brackets, either modules or the ligature ties must be used to activate the force into the bracket which is supposed to be a nidus for bacterial accumulation. However, there are some studies that claim that self-ligating brackets harvest more bacteria in comparison to conventional brackets. ${ }^{16}$ Many studies have compared the plaque index, gingival index, gingival bleeding index and gingival crevicular fluid volume in two separate groups of patients with conventional and self-ligating brackets. The study has shown mixed results. ${ }^{11,16-18}$

In Nepal including the orthodontic unit of Dental Department of National Academy of Medical Sciences (NAMS), the most common brackets used are the conventional brackets and generally modules and ligature ties are used for activation of force to the teeth rather than the locking slots of the self-ligating brackets. The main advantage of conventional bracket is the cheaper price. Though previous studies have shown mixed results regarding its effect on periodontal parameters, no any studies have done in the context of Nepalese patients., 3, 9,16 All the previous studies are done in the western world and on different bracket system which may not be relevant to our context here in Nepal because of the paying capacity of the patient, the oral hygiene habits of the patients and the limited budget to our hospital.

This study aims to find out if there is any difference in the alteration of periodontal parameters (Gingival Index and Plaque Index) with conventional brackets and the self -ligating brackets.

\section{MATERIALS AND METHOD}

The sample of this study included subjects with moderate crowding, non extraction case, no any previous orthodontic treatment, good oral hygiene with no any periodontal problems, no any caries and no any restoration. This study was conducted over a period of six months from March 2018 to August 2018. Subjects with severe crowding needing extraction for orthodontic treatment, previous orthodontic treatment, poor oral hygiene, presence of dental restoration or existing periodontal problems, presence of dental caries or missing teeth due to caries were excluded. The selection of the subjects fulfilling the criteria for the research were done by three orthodontists. If conflict occurred between the orthodontists for any case selection, the cases were discarded. A total number of 20 patients were shorted from the waiting list meeting the above criteria. With the help of random number generator, two groups with 10 subjects each were created for conventional brackets (0.022 Slot MBT brackets) and self-ligating brackets (0.022 Slot DAMON prescription) respectively. The appliance type was kept on a sealed envelope and was opened for the respective patients once they have accepted to be enrolled in the experiment. Approval from the Ethical committee was taken from the university and consent were taken from the patients as well as their parents (if minor) before the subjects were enrolled in the research. All the patients were given oral hygiene instructions one month before the start of the orthodontic treatment. Oral hygiene instructions included proper technique for tooth brushing and the use of interdental brushes. Re-enforcement of the oral hygiene instructions were given throughout the treatment process. All the patients were restricted for using any mouthwashes throughout the treatment. All the subjects were evaluated for the periodontal parameters by a periodontist before orthodontic procedures and those parameters were taken as control.

The patients were blinded regarding the selection of the brackets. All the periodontal parameters (Gingival index and plaque index) were taken before the placement of the brackets (TO). The brackets were bonded according to the random number allocation. After the bonding, the periodontal parameters i.e. gingival index (GI), plaque Index (PI) were measured again at an interval of 60 (TI) and 120 days (T2). Periodontal indices were calculated by summing the mean score of each examined tooth and dividing by the number of the evaluated teeth. The mean of all the measurements for each patient was considered.

Data collection was done with the help of a periodontal probe. The probe was used in all the aspects of the teeth. 


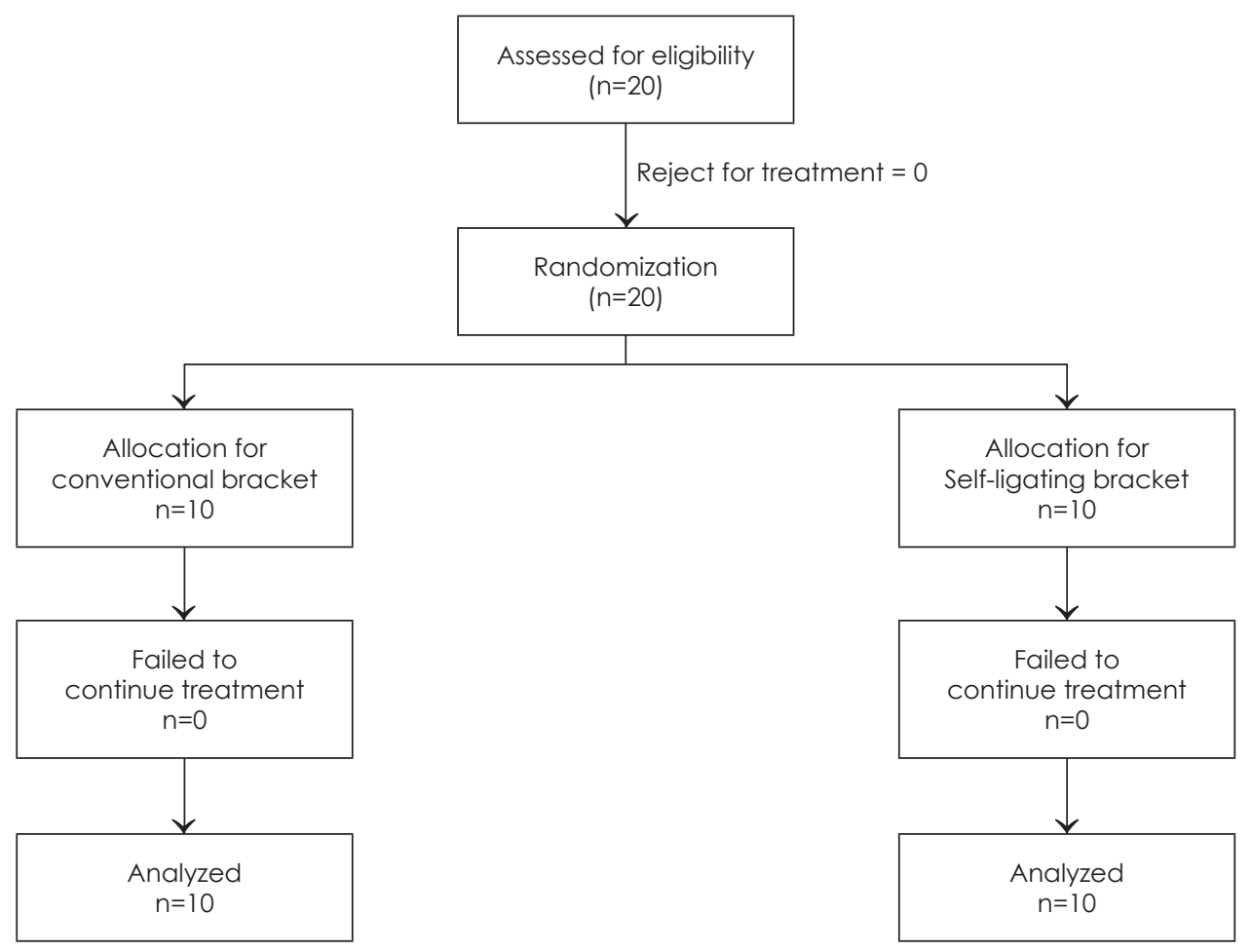

All the records were taken by the same periodontist to avoid inter-examiner variability. To reassure that there is no any intra-examiner variation for periodontal status, the same periodontist re-measured the periodontal parameters again of 10 individuals selected randomly after 7 days from the initial measurements.

SPSS software 21 version were used to input and analysis the data. To examine the intra-examination variability, Dahlberg's formula was used between the two readings taken at a span of 7 days of the same subjects. The mean value of Plaque index and Gingival index was checked for normal distribution applying Kolmogorov-Smirnov test. One-way ANOVA test was applied for comparison between and within groups for plaque index and Gingival index during three different times (TO, T1 and T2) in Conventional brackets and Selfligating brackets (Table 1 and 2). Post hoc Bonferroni test was applied for multiple comparison (Table 3). All data were test were analyzed at $\mathrm{P}<0.05$.

\section{RESULT}

Dahlberg's formula used to compare intra-examiner variability was found to be in the range of 0.4 to 0.6 between the two readings taken at a span of 7 days of the same subjects. Kolmogorov-Smirnov test for normality distribution was found to be insignificant.

Table 1: Comparison of gingival index and plaque index between and within groups of conventional brackets using ANOVA test

\begin{tabular}{|c|c|c|c|c|c|c|}
\hline \multicolumn{2}{|c|}{} & Sum of Squares & df & Mean Square & F & Sig. \\
\hline \multirow{3}{*}{$\begin{array}{c}\text { Conventional } \\
\text { Brackets PI }\end{array}$} & Between Groups & 1.395 & 2 & 0.697 & 4.823 & 0.016 \\
\cline { 2 - 7 } & Within Groups & 3.904 & 27 & 0.145 & & \\
\cline { 2 - 7 } & Total & 5.299 & 29 & & 5.522 & 0.010 \\
\hline \multirow{3}{*}{$\begin{array}{c}\text { Conventional } \\
\text { Brackets GI }\end{array}$} & Between Groups & 2.723 & 2 & 1.361 & & \\
\cline { 2 - 7 } & Within Groups & 6.656 & 27 & 0.247 & & \\
\cline { 2 - 7 } & Total & 9.379 & 29 & & & \\
\hline
\end{tabular}


Table 2: Comparison of gingival index and plaque index between and within groups of self-ligating brackets using ANOVA test

\begin{tabular}{|c|c|c|c|c|c|c|}
\hline \multicolumn{2}{|c}{} & Sum of Squares & df & Mean Square & F & Sig. \\
\hline \multirow{3}{*}{$\begin{array}{c}\text { Self-Ligating } \\
\text { brackets PI }\end{array}$} & Between Groups & 0.926 & 2 & 0.463 & 9.267 & 0.001 \\
\cline { 2 - 7 } & Within Groups & 1.349 & 27 & 0.050 & & \\
\cline { 2 - 7 } & Total & 2.275 & 29 & & 9.575 & 0.001 \\
\hline \multirow{2}{*}{$\begin{array}{c}\text { Self-Ligating } \\
\text { Brackets Gl }\end{array}$} & Between Groups & 2.355 & 2 & 1.177 & & \\
\cline { 2 - 7 } & Within Groups & 3.320 & 27 & 0.123 & & \\
\cline { 2 - 7 } & Total & 5.675 & 29 & & & \\
\end{tabular}

Table 3: Post Hoc test (Bonferroni)

\begin{tabular}{|c|c|c|c|c|c|c|c|}
\hline \multirow{2}{*}{$\begin{array}{l}\text { Dependent } \\
\text { Variable }\end{array}$} & \multirow{2}{*}{ (I) Time } & \multirow{2}{*}{ (J) Time } & \multirow{2}{*}{$\begin{array}{c}\text { Mean } \\
\text { Difference (I-J) }\end{array}$} & \multirow{2}{*}{ Std. Error } & \multirow{2}{*}{ Sig. } & \multicolumn{2}{|c|}{$95 \%$ Confidence Interval } \\
\hline & & & & & & Lower Bound & Upper Bound \\
\hline \multirow{6}{*}{$\begin{array}{l}\text { Self-ligating } \\
\text { Bracket PI }\end{array}$} & 1.00 & 2.00 & -0.23000 & 0.09996 & 0.088 & -0.4852 & 0.0252 \\
\hline & & 3.00 & $-0.43000 *$ & 0.09996 & 0.001 & -0.6852 & -0.1748 \\
\hline & 2.00 & 1.00 & 0.23000 & 0.09996 & 0.088 & -0.0252 & 0.4852 \\
\hline & & 3.00 & -0.20000 & 0.09996 & 0.167 & -0.4552 & 0.0552 \\
\hline & 3.00 & 1.00 & $0.43000 *$ & 0.09996 & 0.001 & 0.1748 & 0.6852 \\
\hline & & 2.00 & 0.20000 & 0.09996 & 0.167 & -0.0552 & 0.4552 \\
\hline \multirow{6}{*}{$\begin{array}{l}\text { Self-ligating } \\
\text { Bracket Gl }\end{array}$} & 1.00 & 2.00 & $-0.42000 *$ & 0.15682 & 0.037 & -0.8203 & -0.0197 \\
\hline & & 3.00 & $-0.68000 *$ & 0.15682 & 0.001 & -1.0803 & -0.2797 \\
\hline & 2.00 & 1.00 & $0.42000 *$ & 0.15682 & 0.037 & 0.0197 & 0.8203 \\
\hline & & 3.00 & -0.26000 & 0.15682 & 0.327 & -0.6603 & 0.1403 \\
\hline & 3.00 & 1.00 & $0.68000^{*}$ & 0.15682 & 0.001 & 0.2797 & 1.0803 \\
\hline & & 2.00 & 0.26000 & 0.15682 & 0.327 & -0.1403 & 0.6603 \\
\hline \multirow{6}{*}{$\begin{array}{c}\text { Conventional } \\
\text { Bracket PI }\end{array}$} & 1.00 & 2.00 & -0.34000 & 0.17005 & 0.167 & -0.7741 & 0.0941 \\
\hline & & 3.00 & $-0.52000^{*}$ & 0.17005 & 0.015 & -0.9541 & -0.0859 \\
\hline & 2.00 & 1.00 & 0.34000 & 0.17005 & 0.167 & -0.0941 & 0.7741 \\
\hline & & 3.00 & -0.18000 & 0.17005 & 0.898 & -0.6141 & 0.2541 \\
\hline & 3.00 & 1.00 & $0.52000^{*}$ & 0.17005 & 0.015 & 0.0859 & 0.9541 \\
\hline & & 2.00 & 0.18000 & 0.17005 & 0.898 & -0.2541 & 0.6141 \\
\hline \multirow{6}{*}{$\begin{array}{c}\text { Conventional } \\
\text { Bracket Gl }\end{array}$} & 1.00 & 2.00 & -0.50000 & 0.22204 & 0.098 & -1.0668 & 0.0668 \\
\hline & & 3.00 & $-0.72000 *$ & 0.22204 & 0.009 & -1.2868 & -0.1532 \\
\hline & 2.00 & 1.00 & 0.50000 & 0.22204 & 0.098 & -0.0668 & 1.0668 \\
\hline & & 3.00 & -0.22000 & 0.22204 & 0.992 & -0.7868 & 0.3468 \\
\hline & 3.00 & 1.00 & $0.72000^{*}$ & 0.22204 & 0.009 & 0.1532 & 1.2868 \\
\hline & & 2.00 & 0.22000 & 0.22204 & 0.992 & -0.3468 & 0.7868 \\
\hline
\end{tabular}

*. The mean difference is significant at the 0.05 level.

Table 4: Independent Samples Test

\begin{tabular}{|c|c|c|c|c|c|c|}
\hline & & \multicolumn{5}{|c|}{ t-test for Equality of Means } \\
\hline & & \multirow{2}{*}{ df } & \multirow{2}{*}{ Sig. (2-tailed) } & \multirow{2}{*}{$\begin{array}{l}\text { Std. Error } \\
\text { Difference }\end{array}$} & \multicolumn{2}{|c|}{$95 \%$ Confidence Interval of the Difference } \\
\hline & & & & & Lower & Upper \\
\hline \multirow{2}{*}{$\mathrm{PI}(\mathrm{T} 1)$} & Self-ligating & 18 & 0.453 & 0.1303 & -0.37375 & 0.17375 \\
\hline & Conventional & 12.003 & 0.458 & 0.1303 & -0.38389 & 0.18389 \\
\hline \multirow{2}{*}{ PI (T2) } & Self-ligating & 18 & 0.492 & 0.11392 & -0.31934 & 0.15934 \\
\hline & Conventional & 10.743 & 0.497 & 0.11392 & -0.33147 & 0.17147 \\
\hline \multirow{2}{*}{$\mathrm{Gl}(\mathrm{Tl})$} & Self-ligating & 18 & 0.577 & 0.21124 & -0.5638 & 0.3238 \\
\hline & Conventional & 13.915 & 0.579 & 0.21124 & -0.57332 & 0.33332 \\
\hline \multirow{2}{*}{$\mathrm{Gl}(\mathrm{T} 2)$} & Self-ligating & 18 & 0.665 & 0.1816 & -0.46152 & 0.30152 \\
\hline & Conventional & 16.165 & 0.665 & 0.1816 & -0.46465 & 0.30465 \\
\hline
\end{tabular}


It was interesting to find that $\mathrm{Pl}$ and $\mathrm{Gl}$ were not statistically significant within 2 months period in both conventional brackets and self-ligating brackets. But when compared in relation to 4 months, the readings are statistically significant within the group for both conventional brackets and self-ligating brackets (Table 3)

However, it was found to be insignificant between the groups (self-ligating and conventional brackets) in both 2 months and $4 \mathrm{~m}$ months period. (Table 4)

\section{DISCUSSION}

The most common method for orthodontic treatment is by using fixed appliance. The duration for orthodontic treatment may last up to years. The fixed appliances hamper the normal efficiency of brushing and hence orthodontist regularly reinforce the patients to maintain a good oral hygiene throughout their treatment. Preventive measures are taken to control the extent of biofilm on the tooth surface by means of using mouthwashes and regular oral prophylaxis to prevent enamel demineralization and gingivitis. There are also marketing campaign by certain company advocating certain types of brackets claiming the superiority of certain brackets over the other. There is a claim that self-ligating brackets provide more hygiene friendly environment than conventional brackets as these brackets have inbuilt locking system and does not require ligature wires and elastic modules. This study was done in order to find out the periodontal status in patients using conventional brackets and selfligating brackets. Many studies have been done to find out the status, but no randomized control studies were found the in the literature. ${ }^{19-22}$ So, in this study, a group of 10 subjects each was randomized for selfligating brackets and conventional brackets and the periodontal status were measured just before bracket placement (TO) and then at 60 days (T1) and 90 (T2) during the treatment. On every appointment, the patients were re-enforced for oral hygiene instructions and were strictly advised not to use any mouthwash at least during the study period.

Gingival Index: Proper oral hygiene was reinforced at every visit so that the patient would maintain good oral hygiene. Minimal crowding was only included in this study so that the crowding would not affect the effectiveness of the oral hygiene maintenance. The gingival index was found to be increased between T0 and $\mathrm{Tl}$ in both $\mathrm{CB}$ and SLB. However, the increment was not statistically significant in both the groups. Similarly, though the measurement for GI was found to be increased between $\mathrm{T} 1$ and $\mathrm{T} 2$ in both the groups, it was also not statistically significant. However, the measured value was found to be significant when compared with $\mathrm{TO}$ and $\mathrm{Tl}$ in both the groups that is at a span of 120 days from the time from bonding the brackets. When the gingival index was compared between CB and SLB brackets at both $\mathrm{T} 1$ and $\mathrm{T} 2$, it was found to be statistically insignificant.

Plaque Index: Similar to the gingival index, the PI was also found to be increased between $\mathrm{TO}$ and $\mathrm{T} 1$ in both CB and SLB though the increased measurement was not found to be statistically significant. Likewise, there is an increment in the measurement between $\mathrm{T} 1$ and $\mathrm{T} 2 \mathrm{in}$ both the groups, but it was not found to be statistically significant. However, the comparison between TO and T2 was found to be statistically significant between both CB and SLB groups. Similarly, comparison between SLB and CB in terms of plaque index was found to be statistically insignificant in both $\mathrm{T} 1$ and T 2 period.

Our finding is in coordination with the findings of Pandis $\mathrm{N}$ et al ${ }^{23}$ who concluded that there is no any significant difference in periodontal status between self-ligating and conventional brackets. Similarly, another study done by Pandis $\mathrm{N}$ et $\mathrm{al}^{24}$ also concluded that there is no any difference in the level of $\mathrm{S}$. mutans in the whole saliva of orthodontically treated patients between selfligating brackets and conventional brackets. The selfligating mechanism might in fact prevent the plaque from being removed from the closing mechanism and thus preventing it from cleaning. However, our finding is in contrast with the findings of Van Gastel et $a^{25}$ who concluded that the periodontal status may alter depending on the bracket design. However, gingival bleeding was not found to be difference between the two groups when probing. Though the study was randomized clinic trial, clinical periodontal parameters recorded in this study was within a short span of 3 and 7 days and the sample size were limited to 16 dental students. Similarly, study done by Begamy et al ${ }^{16}$ showed that self-ligating brackets had more increase in plaque index in comparison to conventional brackets. The study was done in a span of 60 days. However, in this study, self-ligating brackets were limited to 
maxillary anterior teeth only. Another study done by Begamy et al." showed that brackets design plays a significant role in developing periodontal disease with self-ligating brackets showing highest incidence percentage of orange complex bacteria within 60 days after bonding.

All the difference that were noted in our study in comparison to other in the literature might be due to the difference in sample size, sample teeth, age factor, different oral hygiene level, variation of brackets size and design, time duration for record registration, bonding procedure, types of ligation etc. Though self-ligating brackets claim to be more oral hygiene friendly, there is no any evidence for this claim. In fact, the closing mechanism of self-ligating may be the potential location for microbial harvest site due to its inaccessibility to brushing. Our study suggest that bracket design does not have a significant role in periodontal status of the patient. Hence, oral hygiene should be re-enforced time to time to the patient which does agrees with several literature reports. ${ }^{26,27}$

\section{CONCLUSION}

There are no any differences between gingival index and plaque index between self-ligating brackets and conventional brackets. The self-ligating brackets have no any advantages over conventional brackets in terms of periodontal status of the patient.

\section{ACKNOWLEDGEMENT}

This research is done by the grant provided by National academy of Medical Sciences, Bir hospital

\section{REFERENCES}

1. Socransky SS, Haffajee AD, Cugini MA, Smith C, Kent RL, Jr. Microbial complexes in subgingival plaque. J Clin Periodontol 1998;25(2):134-44.

2. Socransky SS, Haffajee AD. Periodontal microbial ecology. Periodontol 2000 2005;38:135-87.

3. Papapanou PN. Population studies of microbial ecology in periodontal health and disease. Ann Periodontol 2002;7(1):54-61.

4. Azuma M. Fundamental mechanisms of host immune responses to infection. J Periodontal Res 2006;41 (5):361-73.

5. Lamster IB. The Host Response in Gingival Crevicular Fluid: Potential Applications in Periodontitis Clinical Trials. J Periodontol 1992;63 Suppl 12S:1117-23.

6. Armitage GC, Cullinan MP. Comparison of the clinical features of chronic and aggressive periodontitis. Periodontol 2000 $2010 ; 53: 12-27$.

7. Andrucioli MC, Nelson-Filho P, Matsumoto MA, et al. Molecular detection of in-vivo microbial contamination of metallic orthodontic brackets by checkerboard DNA-DNA hybridization. Am J Orthod Dentofacial Orthop 2012;141(1):24-9.

8. Anhoury P, Nathanson D, Hughes CV, et al. Microbial profile on metallic and ceramic bracket materials. Angle Orthod 2002;72(4):338-43.

9. Leung NM, Chen R, Rudney JD. Oral bacteria in plaque and invading buccal cells of young orthodontic patients. Am J Orthod Dentofacial Orthop 2006;130(6):698 e11-8.

10. Magno AF, Enoki C, Ito IY, et al. In-vivo evaluation of the contamination of Super Slick elastomeric rings by Streptococcus mutans in orthodontic patients. Am J Orthod Dentofacial Orthop 2008;133(4 Suppl):S104-9.

11. Bergamo AZN, Nelson-Filho P, Andrucioli MCD, et al. Microbial complexes levels in conventional and self-ligating brackets. Clin Oral Investig 2017;21 (4):1037-46.

12. Chhibber A, Agarwal S, Yadav S, Kuo CL, Upadhyay M. Which orthodontic appliance is best for oral hygiene? A randomized clinical trial. Am J Orthod Dentofacial Orthop 2018;153(2):175-83.

13. Lombardo L, Ortan YO, Gorgun O, et al. Changes in the oral environment after placement of lingual and labial orthodontic appliances. Prog Orthod 2013;14:28.

14. Montasser MA, El-Bialy T, Keilig L, et al. Force loss in archwire-guided tooth movement of conventional and self-ligating brackets. Eur J Orthod 2014;36(1):31-8.

15. Jung WS, Kim K, Cho S, Ahn SJ. Adhesion of periodontal pathogens to self-ligating orthodontic brackets: An in-vivo prospective study. Am J Orthod Dentofacial Orthop 2016;150(3):467-75.

16. Bergamo AZ, Nelson-Filho P, Romano FL, et al. Gingival crevicular fluid volume and periodontal parameters alterations after use of conventional and self-ligating brackets. J Orthod 2016;43(4):260-67.

17. Bergamo AZN, Nelson-Filho $P$, do Nascimento $C$, et al. Cytokine profile changes in gingival crevicular fluid after placement different brackets types. Arch Oral Biol 2018;85:79-83.

18. Bergamo AZN, de Oliveira KMH, Matsumoto MAN, et al. Orthodontic appliances did not increase risk of dental caries and periodontal disease under preventive protocol. Angle Orthod 2019:89(1):25-32.

19. Alves de Souza R, Borges de Araujo Magnani MB, Nover DF, et al. Periodontal and microbiologic evaluation of 2 methods of archwire ligation: ligature wires and elastomeric rings. Am J Orthod Dentofacial Orthop 2008;134(4):506-12.

20. Bergamo AZN, Matsumoto MAN, Nascimento CD, et al. Microbial species associated with dental caries found in saliva and in situ after use of self-ligating and conventional brackets. J Appl Oral Sci 2019;27:e20180426. 
21. Sfondrini MF, Gandini P, Castroflorio T, et al. Buccolingual Inclination Control of Upper Central Incisors of Aligners: A Comparison with Conventional and Self-Ligating Brackets. Biomed Res Int 2018;2018:9341821.

22. Tupinamba RA, Claro CAA, Pereira CA, Nobrega CJP, Claro A. Bacterial adhesion on conventional and self-ligating metallic brackets after surface treatment with plasma-polymerized hexamethyldisiloxane. Dental Press J Orthod 2017:22(4):77-85.

23. Pandis N, Vlachopoulos K, Polychronopoulou A, Madianos P, Eliades T. Periodontal condition of the mandibular anterior dentition in patients with conventional and self-ligating brackets. Orthod Craniofac Res 2008;1 1 (4):21 1-5.

24. Pandis N, Papaioannou W, Kontou E, et al. Salivary Streptococcus mutans levels in patients with conventional and self-ligating brackets. Eur J Orthod 2010;32(1):94-9.

25. van Gastel J, Quirynen M, Teughels W, Coucke W, Carels C. Influence of bracket design on microbial and periodontal parameters in vivo. J Clin Periodontol 2007;34(5):423-31.

26. Sukontapatipark W, el-Agroudi MA, Selliseth NJ, Thunold K, Selvig KA. Bacterial colonization associated with fixed orthodontic appliances. A scanning electron microscopy study. Eur J Orthod 2001;23(5):475-84.

27. Smiech-Slomkowska G, Jablonska-Zrobek J. The effect of oral health education on dental plaque development and the level of cariesrelated Streptococcus mutans and Lactobacillus spp. Eur J Orthod 2007;29(2):157-60. 